\title{
Homogenization heat treatment of 2099 Al-Li alloy
}

\author{
Fei Zhang*, Jian Shen, Xiao-Dong Yan, \\ Jian-Lin Sun, Xiao-Long Sun, Yin Yang
}

Received: 16 October 2012/Revised: 14 January 2013/Accepted: 25 January 2013/Published online: 6 August 2013

(C) The Author(s) 2013. This article is published with open access at Springerlink.com

\begin{abstract}
The microstructure evolution and composition distribution of as-cast and homogenized 2099 aluminumlithium (Al-Li) alloy were studied by optical microscopy $(\mathrm{OM})$, differential thermal analysis (DTA), scanning electron microscopy (SEM), energy dispersive spectrometry (EDS), area and line scanning, X-ray diffraction (XRD), and Vickers microhardness test methods. The results show that severe dendrite exists in the as-cast alloy. $\mathrm{Cu}, \mathrm{Zn}, \mathrm{Mn}$, and $\mathrm{Mg}$ distribute unevenly from the grain boundary to inside. The low-melting point nonequilibrium eutectic phases dissolve into the matrix during the first-step homogenization, whereas the melting point of residual eutectic phases is elevated. After the second-step homogenization, most of the remaining eutectic phases dissolve into the matrix, except a small amount of $\mathrm{Al}-\mathrm{Cu}-\mathrm{Fe}$ phases. An optimized homogenization process of the $2099 \mathrm{Al}-\mathrm{Li}$ alloy is developed $\left(515{ }^{\circ} \mathrm{C} \times 18 \mathrm{~h}+525^{\circ} \mathrm{C} \times 16 \mathrm{~h}\right)$, which shows a good agreement with the homogenization kinetic analysis results.
\end{abstract}

Keywords 2099 Al-Li alloy; Homogenization treatment; Nonequilibrium eutectic; Kinetic analysis

\section{Introduction}

Aluminum-lithium (Al-Li) alloys are used commercially in military aircraft and space vehicles in several critical

F. Zhang*, J. Shen, X.-D. Yan, X.-L. Sun, Y. Yang Nonferrous Metals Processing Division, General Research Institute for Nonferrous Metals, Beijing 100088, China e-mail: zffreefly@126.com

F. Zhang, J.-L. Sun

School of Materials Science and Engineering, University of Science and Technology Beijing, Beijing 100083, China applications. However, there is still an interest in developing the next generation of Al-Li alloy with improved specific strength and damage tolerance and reduced mechanical property anisotropy [1]. This interest stemmed from the fact that each $1 \%$ lithium added to the alloy reduced its density by $3 \%$ and increased the elastic modulus by $\sim 5 \%[2,3]$. A representative third-generation $\mathrm{Al}-$ $\mathrm{Li}$ alloy is the $\mathrm{AF} / \mathrm{C} 458$ alloy, which was developed in 1997 and designated as AA 2099 by the Aluminum Association in 2004 [4]. When compared to its predecessor of 2090, 2099 has fewer planar anisotropy, higher transverse ductility, superior stress corrosion cracking resistance, and excellent toughness, and like 2090, it has superb cryogenic properties $[5,6]$.

Studies showed that [7-11] interdendritic segregation during direct chill semicontinuous casting is a serious problem, which has low-melting temperature and dendritic networks morphology and thus, seriously deteriorates the properties of the alloys. Hence, to improve the composition homogeneity and the properties, the ingots of this kind of alloys need homogenization treatment after casting. Homogenization treatment is a crucial process to remove the microsegregation and dissolve large soluble nonequilibrium intermetallic phases, which are formed in rapid solidification processing [12].

Owing to the high content of alloying elements in 2099 $\mathrm{Al}-\mathrm{Li}$ alloy, it is important to investigate its evolution of eutectic phases and to develop an appropriate homogenization process for actual industrial application. In the present work, microstructure evolution and composition distribution of as-cast and homogenized $2099 \mathrm{Al}-\mathrm{Li}$ alloy were studied; the soaking time and temperature of the firststep and second-step homogenization processes were determined, respectively; the kinetic equation of the homogenization was derived. 
Table 1 Chemical composition of 2099 Al-Li alloy (wt\%)

\begin{tabular}{lllllll}
\hline $\mathrm{Cu}$ & $\mathrm{Li}$ & $\mathrm{Zn}$ & $\mathrm{Mg}$ & $\mathrm{Mn}$ & $\mathrm{Zr}$ & $\mathrm{Al}$ \\
\hline 2.60 & 1.75 & 0.64 & 0.29 & 0.30 & 0.08 & $\mathrm{Bal}$. \\
\hline
\end{tabular}

\section{Experimental}

The semicontinuous 2099 ingot was provided by Southwest Aluminum (Group) Co., Ltd. The ingot dimension is $\Phi$ $540 \mathrm{~mm} \times 1,000 \mathrm{~mm}$, and the chemical composition is given in Table 1. The specimens with the size of $50 \mathrm{~mm}$ $\times 100 \mathrm{~mm} \times 20 \mathrm{~mm}$ were extracted from the half position between the circular boundary and the center of the ingot.

First, some specimens were homogenized by the firststep homogenization treatment at $515^{\circ} \mathrm{C}$ for $10,14,18$, $22,26,30,34$, and $38 \mathrm{~h}$ and selected a reasonable soaking time $(18 \mathrm{~h})$. Then, the others were homogenized by the second-step homogenization treatment at 515 and $525{ }^{\circ} \mathrm{C}$ for $16 \mathrm{~h}$ and at 535 and $545^{\circ} \mathrm{C}$ for $8 \mathrm{~h}$ based on $515{ }^{\circ} \mathrm{C} \times 18 \mathrm{~h}$, respectively. The purpose of the first-step homogenization is to eliminate the low-melting point nonequilibrium eutectic phases [13,14], and the secondstep homogenization is trying to reduce or eliminate the residual high-melting point nonequilibrium eutectic phases [15].

The nonequilibrium eutectic phases melting temperature were examined by differential thermal analysis (DTA) from room temperature to $700{ }^{\circ} \mathrm{C}$ with a heating rate of $10^{\circ} \mathrm{C} \cdot \mathrm{min}^{-1}$. Microstructures of as-cast and homogenized specimens were observed by optical microscopy (OM) and scanning electron microscopy (SEM). Intermetallic phases and chemical composition of the alloy were analyzed by $\mathrm{X}$-ray diffraction (XRD) and energy dispersive spectrometry (EDS), respectively. Area and line scanning analysis was performed to observe the distribution of the alloying elements in the materials. Vickers microhardness under different homogenization conditions were measured.
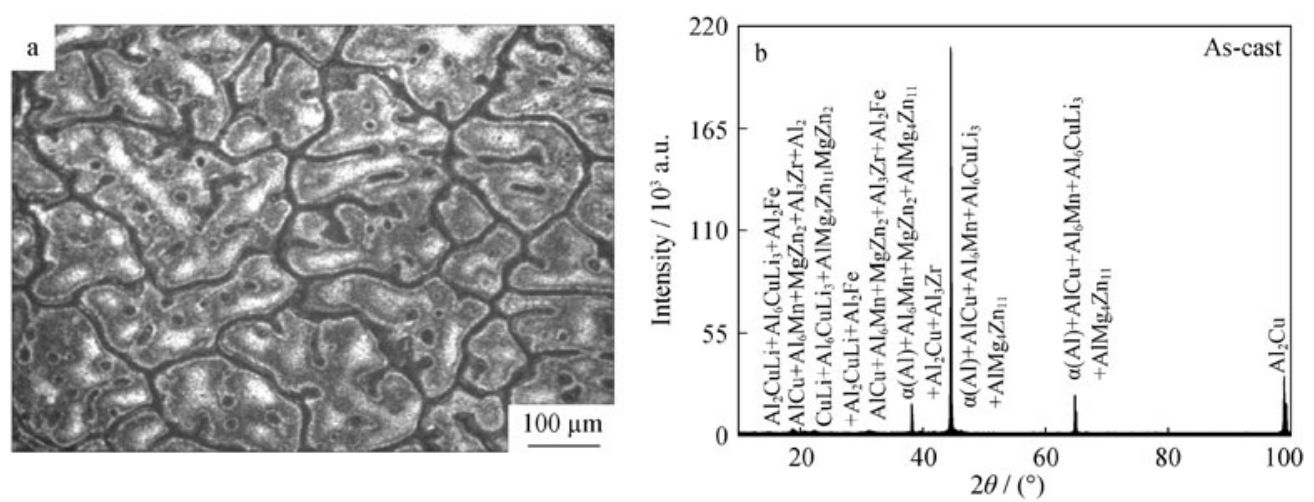

Fig. 1 OM image $\mathbf{a}$ and XRD pattern $\mathbf{b}$ of as-cast alloy

\section{Results and discussion}

\subsection{Characterization of as-cast microstructure}

Figure 1a shows the microstructure of $2099 \mathrm{Al}-\mathrm{Li}$ alloy. It is a typical as-cast eutectic structure exhibiting serious dendritic segregation. The average grain size of as-cast alloy is $\sim 479 \mu \mathrm{m}$. The nonequilibrium eutectic distributes along grain boundaries present continuous networks morphology, which greatly deteriorates the strength and toughness properties of the alloy due to microstructure hereditary. The alloy mainly consists of solid solution $\alpha(\mathrm{Al})$ and binary phases $\mathrm{Al}_{2} \mathrm{Cu}, \mathrm{Al}_{6} \mathrm{Mn}, \mathrm{Al}_{3} \mathrm{Zr}$, and $\mathrm{MgZn}_{2}$ and ternary phases $\mathrm{Al}_{2} \mathrm{CuLi}, \mathrm{Al}_{6} \mathrm{CuLi}_{3}$, and $\mathrm{AlMg}_{4} \mathrm{Zn}_{11}$ (Fig. 1b), which are distributed in grains and along grain boundaries.

As shown in Fig. 2, the alloying elements $\mathrm{Cu}, \mathrm{Mg}$, and $\mathrm{Zn}$ are significantly enriched in grain boundaries, and the element concentration decreases from the grain boundary to inside. Therefore, a homogenization treatment is required to reduce or eliminate severe segregation in the ascast alloy.

\subsection{First-step homogenization}

DTA curves of as-cast and the first-step homogenization are shown in Fig. 3. As shown in Fig. 3a, two endothermic peaks are observed in the as-cast alloy, sited at 532 and $645{ }^{\circ} \mathrm{C}$, which are corresponding to the melting temperature of nonequilibrium eutectic and matrix, respectively. The peak at $532{ }^{\circ} \mathrm{C}$ is generally considered as the overheating temperature of the as-cast alloy, so the homogenization treatment temperature of this kind of alloy is always below $532{ }^{\circ} \mathrm{C}$. In the present study, the first-step homogenization temperature is designed at $515{ }^{\circ} \mathrm{C}$, and the soaking time from 10 to $38 \mathrm{~h}$ at intervals of $4 \mathrm{~h}$.

As shown in Fig. 4, after the first-step homogenization, most of the nonequilibrium eutectic phases dissolve into 

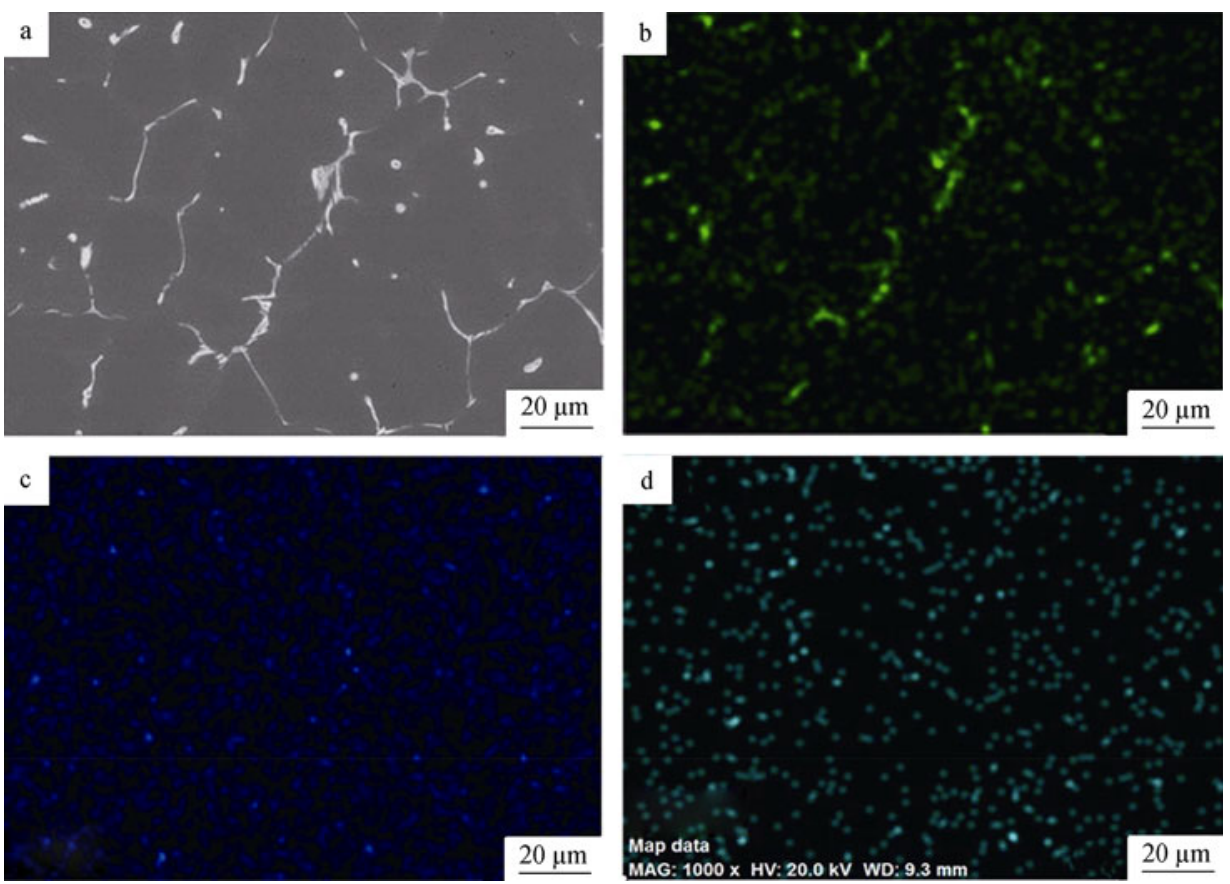

Fig. 2 Area SEM images of as-cast alloy: a SEM image, b $\mathrm{Cu}, \mathbf{c} \mathrm{Mg}$, and $\mathbf{d} \mathrm{Zn}$
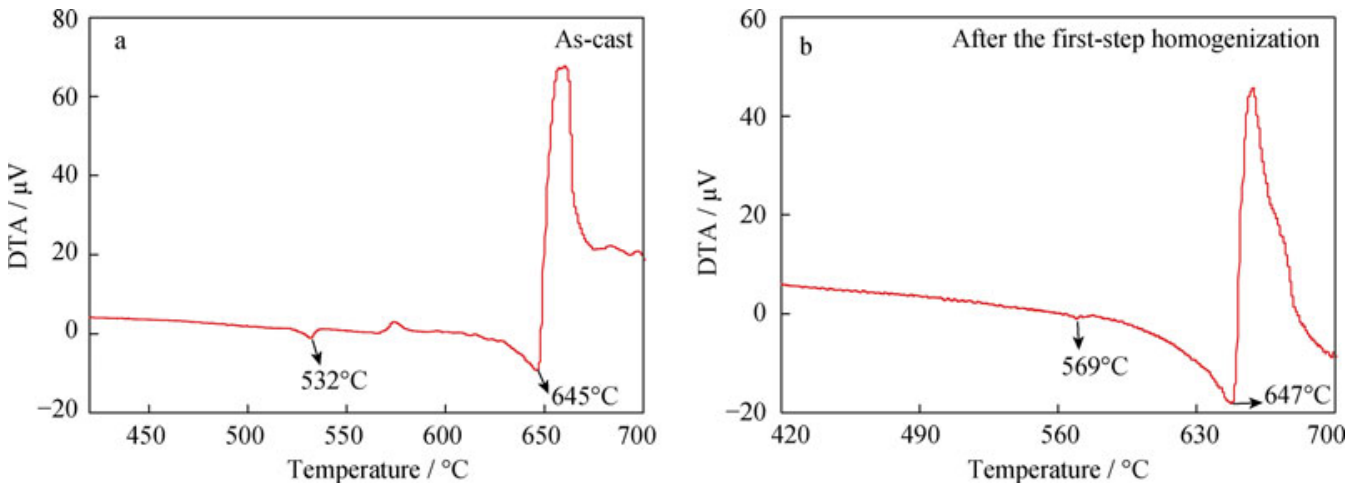

Fig. 3 DTA curves of $\mathbf{a}$ as-cast and $\mathbf{b}$ homogenized $\left(515^{\circ} \mathrm{C} \times 18 \mathrm{~h}\right)$ alloy

the matrix, the grain boundaries are no longer continuous and become thinner, but a small amount of dendrites still exist and there are also some second phases inside the grains. Moreover, the peak sited at $532{ }^{\circ} \mathrm{C}$ vanishes, but another endothermic peak sited at $569^{\circ} \mathrm{C}$ emerges (Fig. 3b). It can be inferred that the low-melting point nonequilibrium eutectic phases are dissolved into the matrix at $515{ }^{\circ} \mathrm{C} \times 18 \mathrm{~h}$, and the residual eutectic melting point rises to $569^{\circ} \mathrm{C}$. Besides with the increase of the soaking time, the change of residual eutectic phases is slightly (Fig. 4a-d), especially over $18 \mathrm{~h}$. This phenomenon indicates that when the soaking time exceeds a certain value, homogenization treatment cannot reduce microstructure segregation effectively.

Vickers microhardness (a load of $500 \mathrm{~g}$ for $20 \mathrm{~s}$ ) was measured on specimens after the first-step homogenization, as shown in Fig. 5. With the increase of soaking time, the hardness value is increased sharply within $18 \mathrm{~h}$. This can be ascribed to the solid solution strengthening for nonequilibrium eutectic phases dissolved into the matrix efficiently during this period. Continue to increase the soaking time (exceed $18 \mathrm{~h}$ ), the hardness value is increased slightly or even decreased. According to the second Fick's law [16, 17], with the increase of soaking time at a certain temperature, the diffusion flux will be reduced with the decrease of the concentration gradient. When the solute atoms distribute evenly, continuing to increase the soaking time will have little effect on the composition segregation, and the segregation extent will not have a further improving. Combining OM observation and microhardness analysis, a proper first-step homogenization process is determined as $515^{\circ} \mathrm{C} \times 18 \mathrm{~h}$. 

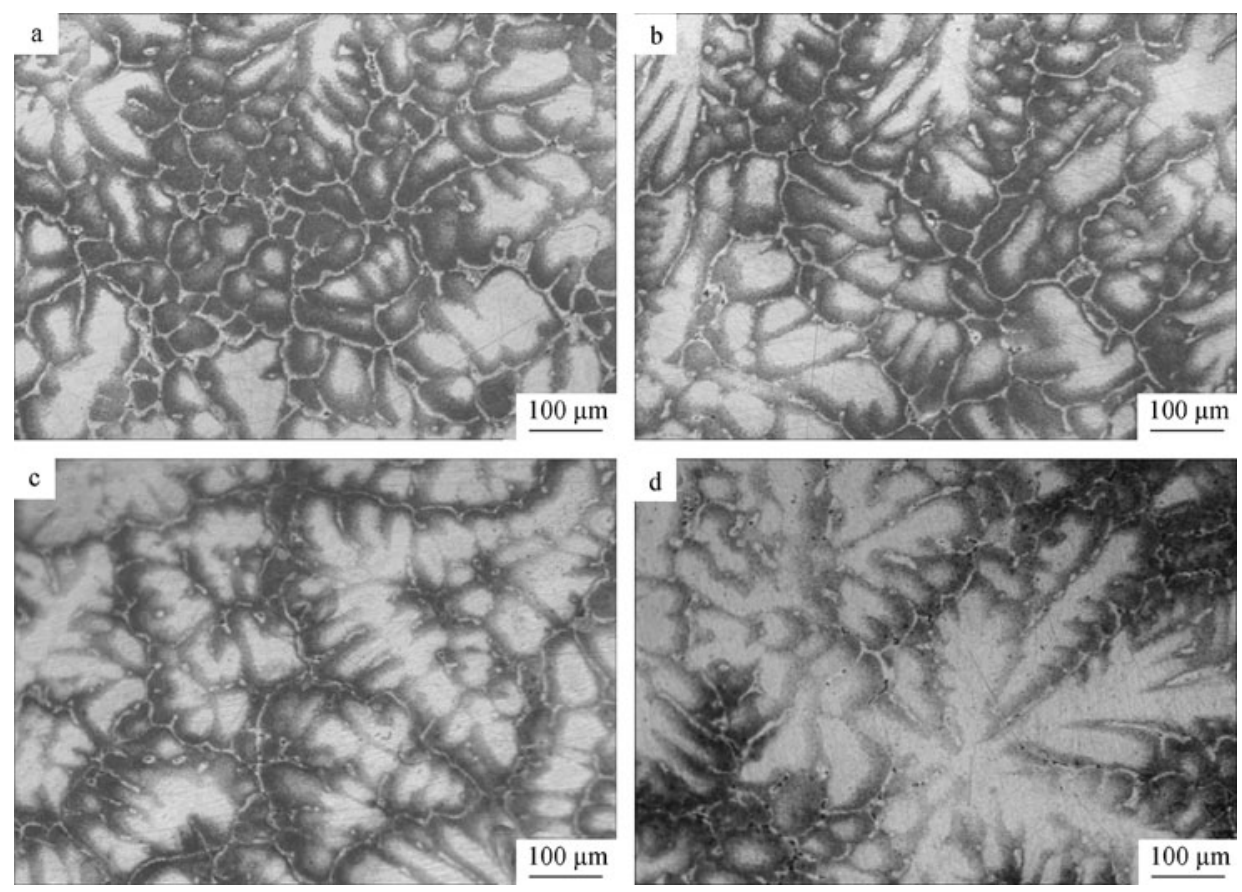

Fig. $4 \mathrm{OM}$ images of alloy homogenized at $515^{\circ} \mathrm{C}$ for different time: a $10 \mathrm{~h}$, b $18 \mathrm{~h}$, c $26 \mathrm{~h}$, and d $34 \mathrm{~h}$

\subsection{Second-step homogenization}

After the first-step homogenization treatment, the residual nonequilibrium eutectic melting point rises to $569{ }^{\circ} \mathrm{C}$. Hence, the temperature for the second-step homogenization should be elevated to further reduce or eliminate the dendrite segregation. As shown in Fig. 6a, b, with elevating the temperature from 515 to $525^{\circ} \mathrm{C}$, the remaining nonequilibrium eutectic decreases, and the dendrite almost eliminates. Moreover, the residual nonequilibrium eutectic phases dissolve sustainably at $535^{\circ} \mathrm{C}$, as shown in Fig. 6c, but a small amount of melting balls appear in the local areas and grain boundaries tend to melt. Further increasing temperature to $545{ }^{\circ} \mathrm{C}$, the number of melting balls increase continuously, and the grain boundaries show

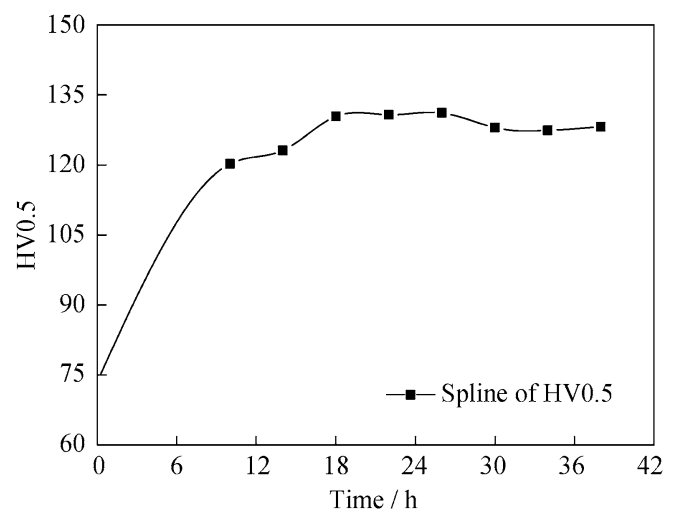

Fig. 5 Vickers microhardness at $515{ }^{\circ} \mathrm{C}$ with different homogenization times intermittent punctuates, which are typical overheating features (Fig. 6d).

As shown in Fig. 7, with the increase of temperature from 515 to $525^{\circ} \mathrm{C}$, the microhardness increases and the maximum value is obtained at $525^{\circ} \mathrm{C}$. However, the hardness decreases as the temperature rises to more than $525{ }^{\circ} \mathrm{C}$. Combining OM observation and microhardness analysis, an optimized second-step homogenization process is determined as $515^{\circ} \mathrm{C} \times 18 \mathrm{~h}+525^{\circ} \mathrm{C} \times 16 \mathrm{~h}$.

Line scanning traces of the as-cast and homogenized alloy are shown in Fig. 8. The peak of the line scanning has two peaks corresponding to a coarse eutectic phase in Fig. 8a, which shows that the alloying elements distribution is uneven within an eutectic phase. Besides, the distribution is also uneven in the dendrite and the extent of segregation is $\mathrm{Cu}>\mathrm{Mn}>\mathrm{Zn}$ (Figs. $4 \mathrm{~b}-\mathrm{d}$ and $8 \mathrm{a}$ ), especially that impurity element $\mathrm{Fe}$ shows a significant segregation in the as-cast structure that has a negative impact on processing and properties. After the first-step homogenization, $\mathrm{Zn}$ segregation is eliminated, Mn distribution is homogeneous from the grain boundary to inside, and only a small amount of $\mathrm{Cu}$ and $\mathrm{Fe}$ is enriched on the grain boundaries (Fig. 8b). After the second-step homogenization, all the alloying elements distribution is homogeneous from the grain boundary to inside and only small segregation of $\mathrm{Cu}$ still exists (Fig. 8c). Therefore, we can conclude that the main alloying elements diffusion velocity is $\mathrm{Zn}>\mathrm{Mn}>\mathrm{Cu}$, and the homogenization temperature to eliminate the main alloying elements segregation is $\mathrm{Cu}>\mathrm{Mn}>\mathrm{Zn}$. 

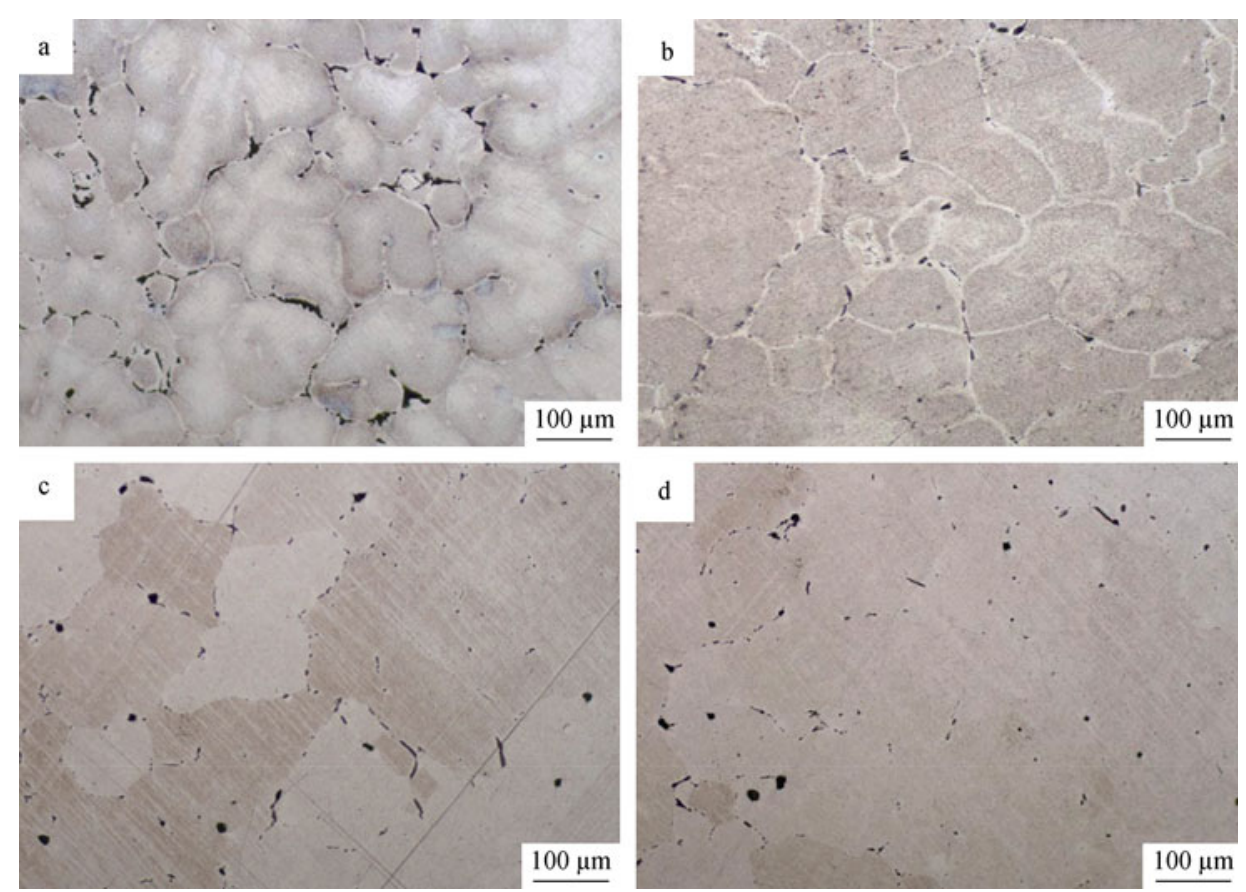

Fig. $6 \mathrm{OM}$ images of alloy homogenized at $515^{\circ} \mathrm{C} \times 18 \mathrm{~h}+\mathbf{a} 515^{\circ} \mathrm{C} \times 16 \mathrm{~h}, \mathbf{b} 525^{\circ} \mathrm{C} \times 16 \mathrm{~h}, \mathbf{c} 535{ }^{\circ} \mathrm{C} \times 8 \mathrm{~h}$, and d $545^{\circ} \mathrm{C} \times 8 \mathrm{~h}$

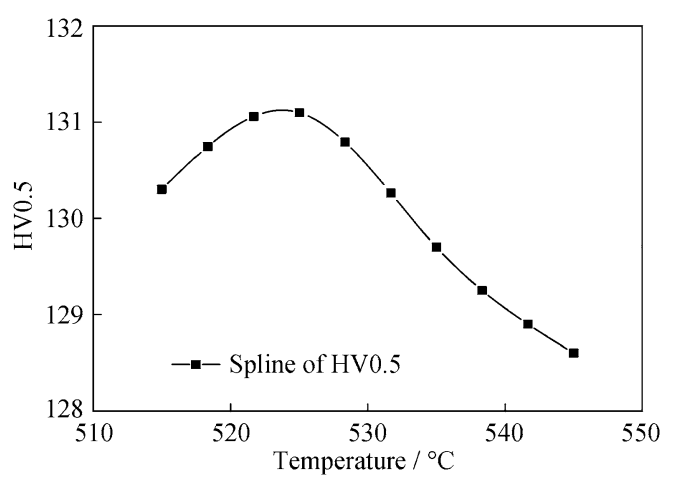

Fig. 7 Vickers microhardness at different temperatures for $16 \mathrm{~h}$

The evolution of eutectic phases of the 2099 alloy during homogenization treatment based on XRD and EDS analyses can be concluded as follows:

After the first-step homogenization as shown in Fig. 9a, the amount of $\mathrm{AlCu}$ phase decreases, $\mathrm{Al}_{6} \mathrm{Mn}$ phase nearly disappears, most of the ternary phases dissolve into the matrix, and some new phases form, such as AlLi and $\mathrm{Al}_{7} \mathrm{Cu}_{3} \mathrm{Mg}_{6}$. Chemical composition analysis (rhombus Nos. 1 and 2 in Fig. 9b), as shown in Fig. 9c, d, indicates that the selected areas are composed of $\mathrm{Al}-\mathrm{Cu}-\mathrm{Fe}$ enriched eutectic phases, such as $\mathrm{Al}_{2} \mathrm{Cu}$ and $\mathrm{Al}_{13} \mathrm{Fe}_{4}$, which are formed during the casting process.

After the second-step homogenization, most of the nonequilibrium eutectic phases dissolve into the matrix. Some phases, such as $\mathrm{Al}_{6} \mathrm{CuLi}_{3}$ and $\mathrm{AlMg}_{4} \mathrm{Zn}_{11}$, are precipitated in the cooling process after homogenization
(Fig. 10a). It can be seen from Fig. 10c, d, the residual eutectic phases (triangle Nos. 1 and 2 in Fig. 10b) are composed of $\mathrm{Al}-\mathrm{Cu}-\mathrm{Fe}$ and $\mathrm{Al}-\mathrm{Cu}$. In addition, $\mathrm{Al}_{3} \mathrm{Zr}$ particles are appearing under this homogenization condition. They are not detected by X-ray due to low content.

\subsection{Homogenization kinetic analysis}

As shown in Fig. 8, the distribution of the main alloying elements along the interdendritic region varies periodically. This variation law can be approximately represented in Fig. 11, where $L$ is the wavelength (interdendritic spacing), $\Delta w_{0}$ is the initial amplitude of the composition segregation, and $\bar{w}$ is the average concentration of the element. Therefore, the studies of diffusion law along dendrite region are important to the investigations of elements distribution during homogenization.

According to Ref. [11], the initial concentration of the elements along the interdendritic region can be approached by Fourier series components in a cosine function:

$w(x)=\bar{w}+A \cos (2 \pi x / L)$

where $A=0.5 \Delta w_{0}$.

According to the second Fick's law $[18,19]$ and the boundary conditions, $w(x, t)$ is given as

$w(x, t)=\bar{w}+0.5 \Delta w_{0} \cos \left[\frac{2 \pi x}{L}\right] \exp \left[-\frac{4 \pi^{2}}{L^{2}} D t\right]$

where $D$ is the diffusion coefficient of the alloying elements in the matrix and $t$ is the diffusion time. 

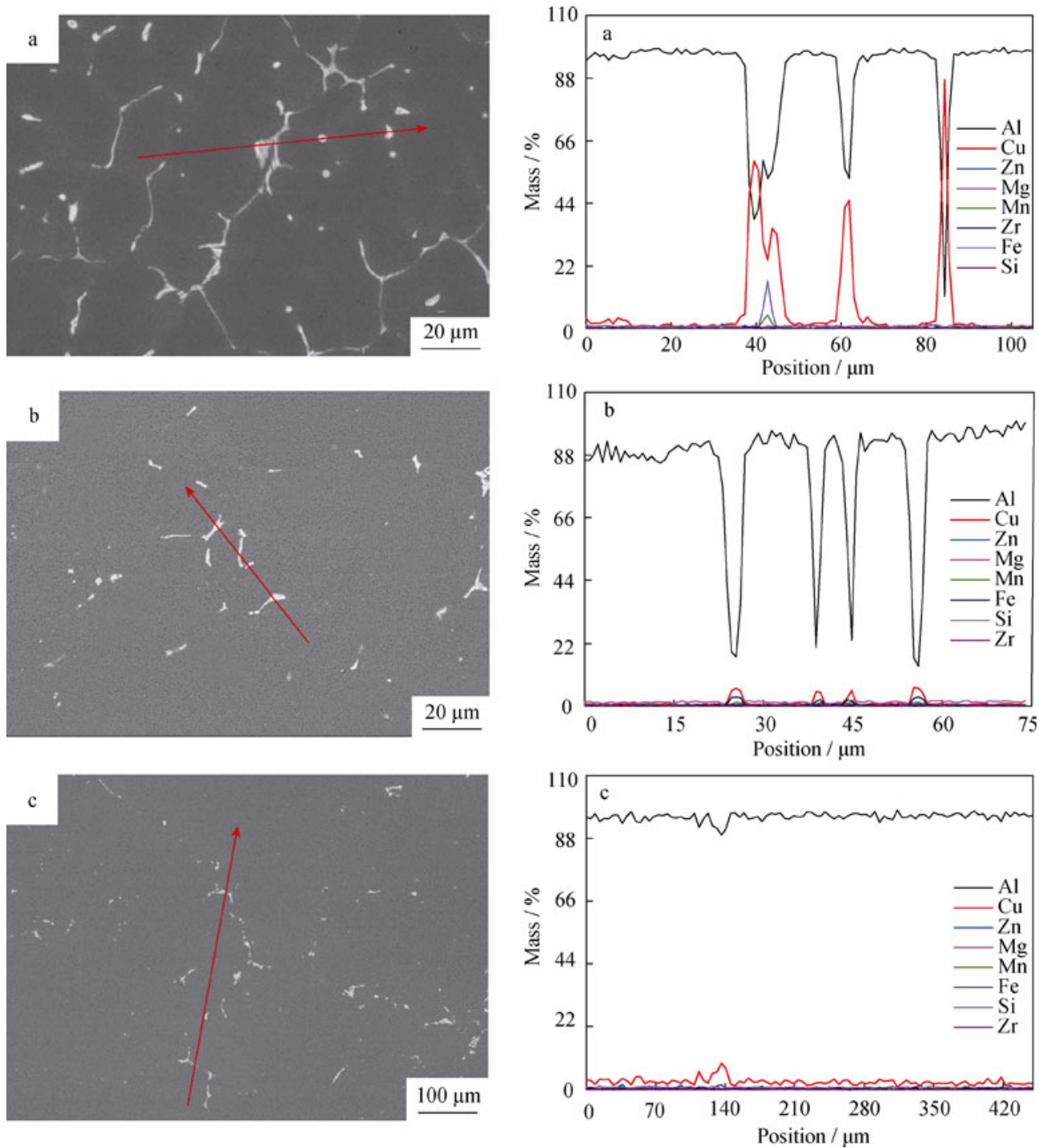

Fig. 8 Line scanning analysis under different conditions: a as-cast, b $515{ }^{\circ} \mathrm{C} \times 18 \mathrm{~h}$, and c $515^{\circ} \mathrm{C} \times 18 \mathrm{~h}+525{ }^{\circ} \mathrm{C} \times 16 \mathrm{~h}$

The cosine distribution attenuation law in Eq. (2) can be described by the attenuation function [20]:

$w(x, t)=0.5 \Delta w_{0} \exp \left[-\frac{4 \pi^{2}}{L^{2}} D t\right]$

Assuming the element distribution is homogeneous when the composition segregation amplitude is reduced to $1 \%$, then

$1 \%=\exp \left[-\frac{4 \pi^{2}}{L^{2}} D t\right]$

Considering the relationship between diffusion coefficient and temperature, $D$ is given as

$D=D_{0} \exp (-Q / R T)$ where $D_{0}$ is independent coefficient, $Q$ is the diffusion activation energy, $R$ is the gas constant, and $T$ is the absolute temperature.

By substituting Eq. (5) into Eq. (4), the equation can be rewritten as:

$\frac{1}{T}=\frac{R}{Q} \ln \left[\frac{4 \pi^{2} D_{0} t}{4.6 L^{2}}\right]$

Assuming $A=R / Q$ and $B=4.6 / 4 \pi^{2} D_{0}$, we can obtain the homogenization kinetic equation:

$\frac{1}{T}=A \ln \left(\frac{t}{B L^{2}}\right)$

As long as the parameters of as-cast microstructure are given, the homogenization kinetic curves can be obtained. 

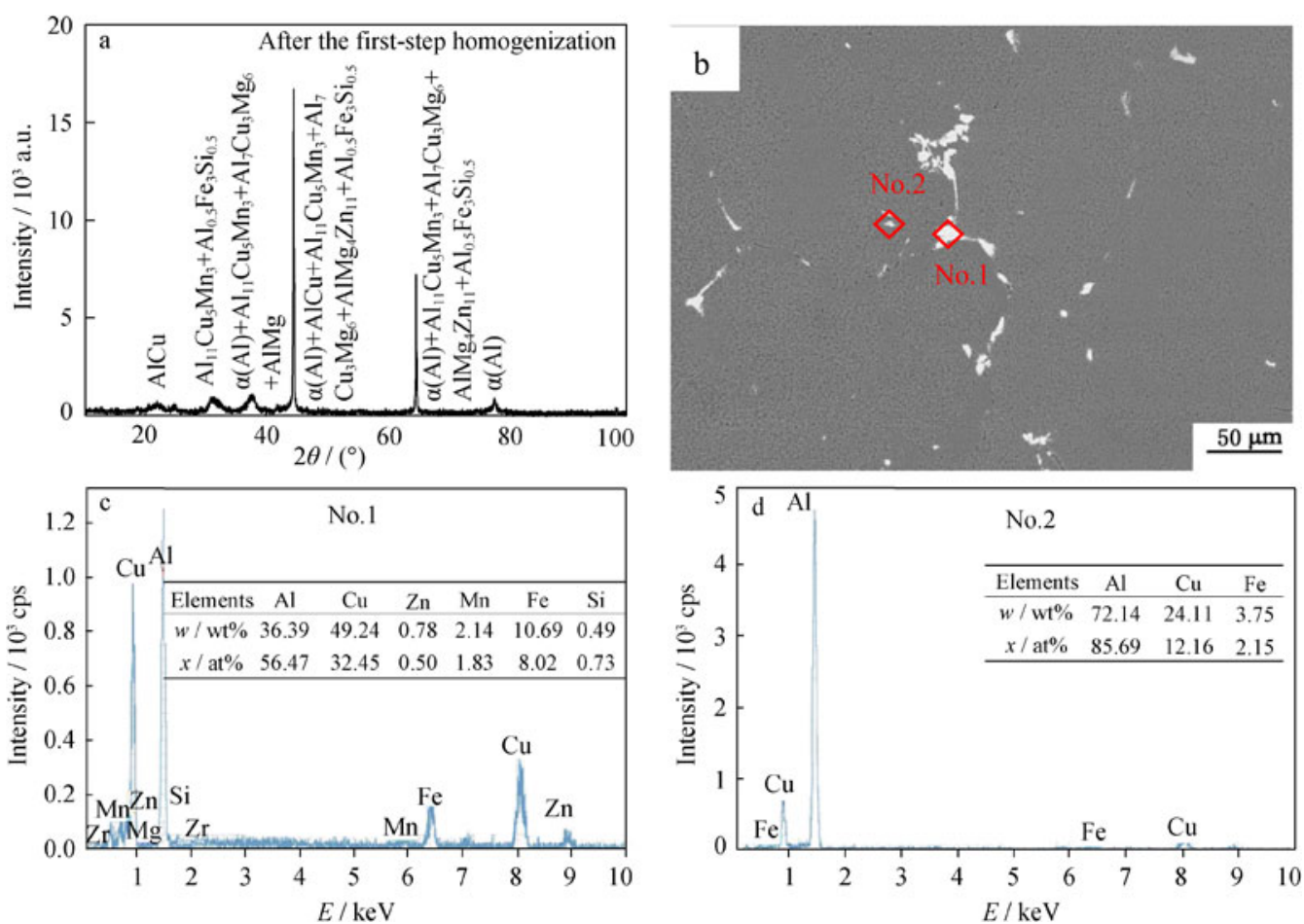

Fig. 9 Phases analysis after the first-step homogenization: a XRD, b SEM, c and d EDS of No.1 and No.2 in b
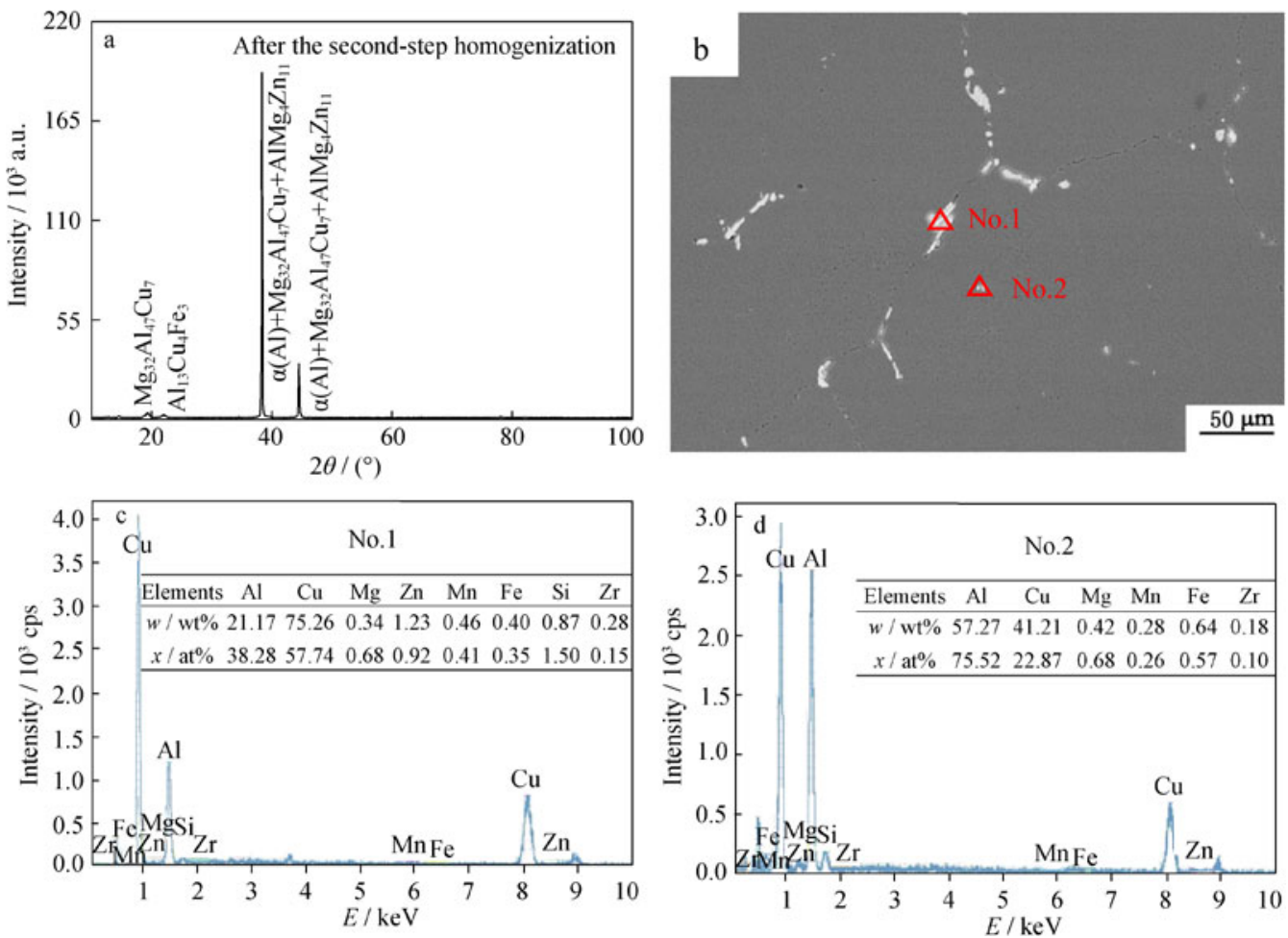

Fig. 10 Phases analyses after the second-step homogenization: a XRD, b SEM, c and $\mathbf{d}$ EDS of No.1 and No.2 in b

From the results of Sect. 3.3, we can know that the diffusion coefficient of $\mathrm{Cu}$ is much lower than $\mathrm{Zn}$ and $\mathrm{Mn}$ at the same temperature. Therefore, the homogenization process is believed to be controlled by the diffusion of $\mathrm{Cu}$. By substitution of $D_{0}(\mathrm{Cu})=0.084 \mathrm{~cm}^{2} \cdot \mathrm{s}^{-1}, Q(\mathrm{Cu})=$ $136.8 \mathrm{~kJ} \cdot \mathrm{mol}^{-1}$, and $R=8.314 \mathrm{~J} \cdot(\mathrm{mol} \cdot \mathrm{K})^{-1}$ into Eq. (7), 


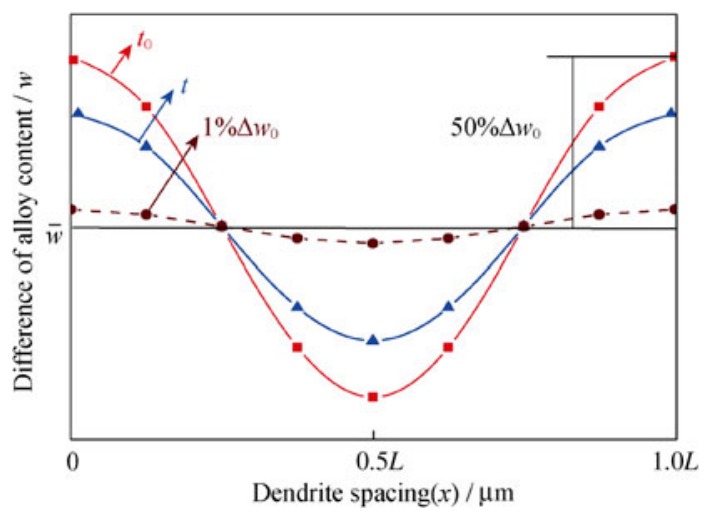

Fig. 11 Elements distribution during process of homogenization

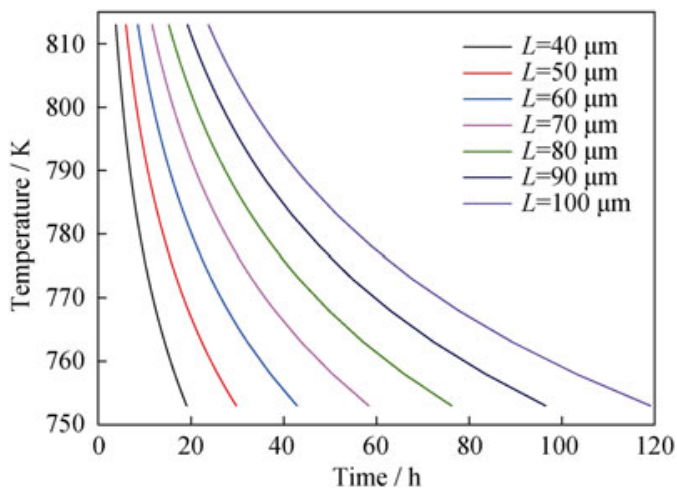

Fig. 12 Curves of homogenization kinetic

the homogenization kinetic curves of 2099 Al-Li alloy for different dendrite spacings can be obtained. As shown in Fig. 12, the soaking time is decreased with the increase of temperature, and microstructure refinement can also greatly shorten the soaking time.

The average dendrite spacing of as-cast and after the first-step homogenization treatment in this study is 65 and $70 \mathrm{~mm}$, respectively, obtained from quantitative metallographic analysis. According to the homogenization kinetic curves, at the optimized temperatures of 515 and $525{ }^{\circ} \mathrm{C}$, the corresponding soaking time are 19.2 and $17.1 \mathrm{~h}$, respectively. This is in good accordance with the experimental results. Besides, we find that there still exist a small amount of remaining eutectic phases in the local areas, and XRD and EDS analysis show that they are consisted of Al$\mathrm{Cu}-\mathrm{Fe}$ phases, owing to its high-melting point that cannot be eliminated in the homogenization process.

\section{Conclusion}

In the present study, $2099 \mathrm{Al}-\mathrm{Li}$ alloy homogenization treatment was carried out by performing the first-step and second-step homogenization treatment in a range of times and temperatures. Severe dendrite segregation exists in the as-cast alloy. The segregation extent of main alloying elements is $\mathrm{Cu}>\mathrm{Mn}>\mathrm{Zn}$.

Low-melting point nonequilibrium eutectic phases dissolve into the matrix at $515{ }^{\circ} \mathrm{C}$ for $18 \mathrm{~h}$, and maximum value $(129 \mathrm{HV} 0.5)$ of microhardness is obtained at $515{ }^{\circ} \mathrm{C}$ for $18 \mathrm{~h}$. The further increase of soaking time has little effect on the microstructure evolution and microhardness changes. Most of residual nonequilibrium eutectic phases dissolve and the dendrite almost eliminates at $525{ }^{\circ} \mathrm{C}$ for $16 \mathrm{~h}$. With the increase of the temperature, some melting balls appear, which is typical overheating features. The optimized second-step homogenization process is determined at $515{ }^{\circ} \mathrm{C} \times 18 \mathrm{~h}+525{ }^{\circ} \mathrm{C} \times 16 \mathrm{~h}$. The segregation is eliminated basically after second-step homogenization. The homogenization kinetic curves have a good consistent with the first-step and second-step homogenization treatment process parameters.

Acknowledgments This work was financially supported by the National Key Basic Research Development Program of China (No. 2012CB619504).

Open Access This article is distributed under the terms of the Creative Commons Attribution License which permits any use, distribution, and reproduction in any medium, provided the original author(s) and the source are credited.

\section{References}

[1] Fragomeni J, Wheeler R, Jata KV. Effect of single and duplex aging on precipitation response, microstructure, and fatigue crack behavior in Al-Li-Cu alloy AF/C-458. J Mater Eng Perform. 2005;50(1):18.

[2] Jabra J, Romios M, Lai J, Lee E, Setiawan M, Lee EW, Witters J, Abourialy N, Ogren JR, Clark R, Oppenheim T, Frazier WE, Es-said OS. The effect of thermal exposure on the mechanical properties of 2099-T6 die forgings, 2099-T83 extrusions, 7075T7651 plate, 7085-T7452 die forgings, 7085-T7651 plate, and 2397-T87 plate aluminum alloys. J Mater Eng Perform. 2006;15(5):601.

[3] Eddahbi M, Thomson CB, Carreno F, Ruano OA. Grain structure and microstructure after high temperature deformation of an Al-Li (8090) alloy. Mater Sci Eng A. 2000;284(1-2):292.

[4] Ma Y, Zhou X, Thompson GE, Hashimoto T, Thomson P, Fowles M. Distribution of intermetallics in an AA 2099-T8 aluminium alloy extrusion. Mater Chem Phys. 2011;126(1-2):46.

[5] Romios M, Tiraschi R, Parrish C, Babel HW, Ogren JR, Es-Said OS. Design of multistep aging treatments of 2099(C458) Al-Li alloy. J Mater Eng Perform. 2005;14(5):641.

[6] Vander Kooi DC, Park W, Hilton MR. Characterization of cryogenic mechanical properties of aluminum-lithium alloy C458. Scripta Mater. 1999;41(11):1185.

[7] Li NK, Cui JZ. Microstructural evolution of high strength 7B04 ingot during homogenization treatment. Trans Nonferrous Met Soc China. 2008;12(5):769.

[8] Wu ZW, Chen Y, Meng L. Microstructure and properties of $\mathrm{Cu}-$ $\mathrm{Fe}$ microcomposites with prior homogenizing treatments. J Alloys Compd. 2009;481(1-2):236. 
[9] Wu LM, Wang WH, Hsub YF, Trong S. Effects of homogenization treatment on recrystallization behavior and dispersoid distribution in an $\mathrm{Al}-\mathrm{Zn}-\mathrm{Mg}-\mathrm{Sc}-\mathrm{Zr}$ alloy. J Alloys Compd. 2008;456(1-2): 163 .

[10] Totik Y, Sadeler R, Kaymaz I, Gavgali M. The effect of homogenization treatment on cold deformations of AA 2014 and AA 6063 alloys. J Mater Process Tech. 2004;147(1):60.

[11] Liu XY, Pan QL, Fan X, He YB, Li WB, Liang WJ. Microstructural evolution of $\mathrm{Al}-\mathrm{Cu}-\mathrm{Mg}-\mathrm{Ag}$ alloy during homogenization. J Alloys Compd. 2009;484(1-2):790.

[12] Wang GJ, Xiong BQ, Zhang TG, Li ZH, Li PY. Microstructural characterization of as-cast and homogenized 2D70 aluminum alloy. Int J Min Met Mater. 2009;16(4):427.

[13] Knipling KE, Karnesky RA, Lee CP, Dunand DC, Seidman DN. Precipitation evolution in Al-0.1Sc, Al-0.1Zr and Al-0.1Sc$0.1 \mathrm{Zr}$ (at\%) alloys during isochronal aging. Acta Mater. 2010;58(15):5184.

[14] Senkov ON, Shagiev MR, Senkova SV, Miracle DB. Precipitation of $\mathrm{Al}_{3}(\mathrm{Sc}, \mathrm{Zr})$ particles in an $\mathrm{Al}-\mathrm{Zn}-\mathrm{Mg}-\mathrm{Cu}-\mathrm{Sc}-\mathrm{Zr}$ alloy during conventional solution heat treatment and its effect on tensile properties. Acta Mater. 2008;56(15):3723.

[15] Jia ZH, Hu GQ, Forbord B, Ketil SJ. Effect of homogenization and alloying elements on recrystallization resistance of $\mathrm{Al}-\mathrm{Zr}$ Mn alloys. Mater Sci Eng A. 2007;444(1-2):284.

[16] Taktak S, Akbulut H. Diffusion kinetics of explosively treated and plasma nitrided Ti-6Al-4V alloy. Vacuum. 2004;75(3):247.

[17] Ding SP, Petuskey WT. Solutions to Fick's second law of diffusion with a sinusoidal excitation. Solid State Ion. 1998; 109(1-2): 101 .

[18] Ujihara T, Fujiwara K, Sazaki G, Usami N, Nakajima K. New method for measurement of interdiffusion coefficient in high temperature solutions based on Fick's first law. J Cryst Growth. 2002;241(3):387.

[19] Samaras SN, Haidemenopoulos GN. Modelling of microsegregation and homogenization of 6061 extrudable Al-alloy. J Mater Process Technol. 2007;194(1-3):63.

[20] Liu GX. Fundamentals of Metallurgy. Beijing: Metallurgical Industry Press; 1980. 283. 